\title{
CERTAIN SUBORDINATION RESULTS INVOLVING A GENERALIZED MULTIPLIER TRANSFORMATION OPERATOR
}

\author{
PoOnAm Sharma, J. K. Prajapat And R. K. RAina
}

\begin{abstract}
This paper investigates various new subordination results for certain $p$-valent analytic functions involving a generalized multiplier transformation operator $J_{p}^{m}(\lambda, l), m \in \mathbb{Z}$, defined recently by J. K. Prajapat [Math. Comput. Modelling, 55 (2012), 1456-1465]. Several lines of approach are followed to obtain the subordination results. We also consider some simpler and precise forms of the derived results.
\end{abstract}

Mathematics subject classification (2010): 30C45, 30C50.

Keywords and phrases: Analytic functions, univalent functions, convolution, subordination.

\section{REFERENCES}

[1] M. Abramowitz And I. A. Stegun (Editors), Handbook of Mathematical Functions and Formulas, Graphs and Mathematical Tables, Dover publications, New York, 1971.

[2] M. K. Aouf, A. O. Mostafa ANd R. El-Ashwah, Sandwich theorem of analytic functions defined by a certain integral operator, Math. Comp. Modelling, 53 (9-10), (2011), 1647-1653.

[3] A. C̆̆TAŞ, On certain classes of p-valent functions defined by multiplier transformations, in Proceedings of the international Symposium on Geometric Function Theory and Applications: GFTA 2007 (Eds. S. Owa, Y. Polatoglu), TC Istanbul University Publications, Turkey, 2008, pp. 241-250.

[4] J. Dziok AND H. M. SRivastava, Certain subclasses of analytic functions associated with the generalized hypergeometric functions, Integral Transform Spec. Funct., 14 (2003), 7-18.

[5] R. M. El-Ashwah And M. K. Aouf, Some properties of new integral operator, Acta Univ. Apulensis Math. Inform., 24 (2010), 51-61.

[6] D. I. Hallenbeck, St. Ruscheweyh, Subordination by convex functions, Proc. Amer. Math. Soc., 52 (1975), 191-195.

[7] I. B. Jung, Y. C. Kim AND H. M. SRIVASTAVA, The Hardy space of analytic functions associated with certain one-parameter families of integral operators, J. Math. Anal. Appl., 179 (1993), 138-147.

[8] S. S. Kumar, H. C. TANEJA And V. Ravichandran, Classes of multivalent functions defined by Dzoik-Srivastava linear operator and multiplier transformations, Kyungpook Math. J., 46 (2006), 97-109.

[9] Jin-Lin LiU, Notes on Jung-Kim-Srivastava integral operator, J. Math. Anal. Appl., 294 (1), (2004), 96-103.

[10] T. H. Macgregor, The radius of univalence of certain analytic functions, Proc. Amer. Math. Soc., 14 (1963), 514-520.

[11] S. S. Miller, P. T. Mocanu, Differential Subordinations, Theory and Applications, Marcel Dekker Inc., New York, Basel, 2000.

[12] S. S. Miller And P. T. Mocanu, On some classes of first order differential subordination, Michigan Math. J., 32 (1985), 185-195.

[13] H. ORHAN AND H. KizILTUNC, A generalization on subfamily of $p$-valent functions with negative coefficients, Appl. Math.Comput., 155 (2004), 521-530.

[14] J. Patel And P. SAhoo, Certain subclasses of multivalent analytic functions, Indian J. Pure Appl. Math., 34 (3), (2003), 487-500.

[15] J. K. PRAJAPAT, Subordination and superordination preserving properties for generalized multiplier transformation operator, Math. Comput. Modelling, 55 (2012), 1456-1465. 
[16] M. S. Robertson, Certain classes of starlike functions, Michigan Math. J., 32 (1985), 135-140.

[17] W. Rogosins Ki, On the coefficients of subordinate functions, Proc. London Math. Soc., (Ser.2) 48 (1943) 48-82.

[18] G. S. SĂLĂGEAN, Subclasses of univalent functions, Lecture Notes in Math. (Spring-Verlag), 1013 (1983), 362-372.

[19] R. Singh, On Bazilevič functions, Proc. Amer. Math. Soc., 38 (1973), 261-271.

[20] H. M. SRivastava, M. K. Aouf And RM. El-Ashwah, Some inclusion relationships associated with a certain class of integral operators, Asian-Europ. J. Math., 3 (4), (2010), 667-684.

[21] H. M. SRivastava And S. Owa (Editors), Current Topics in Anaytic Function Theory, pp. 266-273, World Scientific Publishing Company, Singapore, New Jersey, London and Hongkong, 1992.

[22] Zhi-Gang Wang, R. Aghalary, M. Darus And R. W. Ibrahim, Some properties of certain multivalent analytic functions involving the Cho-Kwon-Srivastava operator, Math. Comput. Modelling, 49 (2009), 1969-1984. 